\title{
Can the integration of multiple biomarkers and sediment geochemistry aid solving the complexity of sediment risk assessment? A case study with a benthic fish
}

\author{
Pedro M. Costa ${ }^{\mathrm{a}, *}$, Sandra Caeiro ${ }^{\mathrm{a}, \mathrm{b}}$, Carlos Vale ${ }^{\mathrm{c}}$, T. Àngel DelValls ${ }^{\mathrm{d}}$, Maria H. Costa ${ }^{\mathrm{a}}$

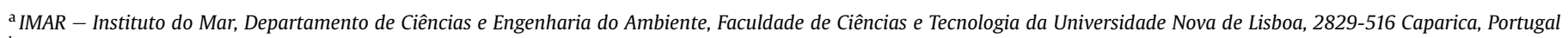 \\ ${ }^{\mathrm{b}}$ Departamento de Ciências e Tecnologia, Universidade Aberta, Rua da Escola Politécnica, 141, 1269-001 Lisboa, Portugal \\ ${ }^{\mathrm{c}}$ IPIMAR - INRB, Instituto Nacional dos Recursos Biológicos, Avenida de Brasília, 1449-006 Lisboa, Portugal \\ d UNESCO/UNITWIN/WiCop Chair - Departamento de Química Física, Facultad de Ciencias del Mar y, Ambientales, Universidad de Cádiz, Polígono río San Pedro s/n, \\ 11510 Puerto Real, Cádiz, Spain
}

\section{A R T I C L E I N F O}

Article history:

Received 11 February 2011

Received in revised form

7 October 2011

Accepted 9 October 2011

\section{Keywords:}

Biomarkers

Bioassays

Sediment quality guidelines

Ecological risk assessment

Solea senegalensis

Sado estuary

\begin{abstract}
A B S T R A C T
Surveying toxicity of complex geochemical media as aquatic sediments often yields results that are either difficult to interpret or even contradictory to acknowledged theory. Multi-level biomarkers were investigated in a benthic fish exposed to estuarine sediments through laboratory and in situ bioassays, to evaluate their employment either in ecological risk assessment or in more mechanistic approaches to assess sediment-bound toxicity. Biomarkers reflecting lesions (such as genotoxicity or histopathology), regardless of their low or absent specificity to contaminants, are efficient in segregating exposure to contaminated from uncontaminated sediments even when classical biomarkers like CYP1A and metallothionein induction are inconclusive. Conversely, proteomics and gene transcription analyses provided information on the mechanics of toxicity and aided explaining response variation as a function of metabolic imbalance and impairment of defences against insult. In situ bioassays, although less expedite and more affected by confounding factors, produced data better correlated to overall sediment contamination.
\end{abstract}

(c) 2011 Elsevier Ltd. All rights reserved.

\section{Introduction}

The need to reconcile socio-economical activities with environmental quality dictates the importance of developing effective ecological monitoring. Estuaries are particular cases of concern due to their ecological importance, complexity and, most frequently, high level of anthropogenic pressure. Estuaries are subjected to multiple sources of different pollutants which, concerning contamination of the water bodies, tend to be trapped in sediments, sorbed to fine particles and organic matter. Estuarine

Abbreviations: 2DE, 2-dimensional electrophoresis; DDD, dichloro-diphenyldichloroethane; DDE, dichloro-diphenyl-dichloroethylene; DDT, dichloro-diphenylthichloroethane; DPP-SMDE, differential pulse polarography with a static mercury drop electrode; Eh, redox potential; ENA, erythrocytic nuclear abnormalities; FC, fold change; FF, sediment fine fraction; GC, gas chromatography; ICP-MS, inductively coupled plasma mass spectrometry; LOI, carbon loss-on-ignition; PAH, polycyclic aromatic hydrocarbon; PCB, polychlorinated biphenyl; PCR, polymerase chain reaction; SQG, sediment quality guideline; SQG-Q, sediment quality guideline quotient; TOM, total organic matter; TSB, total DNA strand breakage.

* Corresponding author.

E-mail address: pmcosta@fct.unl.pt (P.M. Costa). sediments can act, therefore, as reservoirs of contaminants that under certain circumstances may be released back to the water column, rendering them more readily available to the biota (see Chapman, 2007, for a review). Therefore, assessing sediment quality, of which toxicity testing is one of the lines-of-evidence (LOEs), is a key element in ecological risk assessment (ERA) strategies for these ecosystems. One can refer, for instance, to the sediment quality triad concept proposed by Long and Chapman (1985), which integrates sediment chemistry, ecological changes to benthic fauna and toxicity testing as fundamental LOEs for risk assessment of aquatic sediments.

Testing the toxicity of estuarine sediments, however, is a challenge to environmental toxicologists, in part due to the geochemical complexity of estuarine sediments (which affects contaminant speciation and bioavailability) and in part caused by the likely existence of multiple types of xenobiotics which can mask cause-effect relationships by within-organism interaction effects. To these constraints can be added the complex biological effects and responses to contamination. The biomarker approach has been widely employed in ERA, for both predictive and mechanist toxicological studies. Biomarkers, in practical terms, are regarded as "early 
warnings" of the potential adverse effects caused by xenobiotics to organisms (refer to van der Oost et al., 2003 for a review on the use of biomarkers in aquatic organisms for ERA). In fact, the archetypal definition for "biomarker" in environmental research, as defined by van Gestel and van Brummelen (1996), stands for any sub-individual level alterations resulting from exposure to a given substance. There is a constant need to search and validate adequate biomarkers in toxicity testing for ecotoxicological studies, with especial respect to contaminant mixtures. In the past decade, the novel "omic" approaches (transcriptomics/toxicogenomics, proteomics and metabolomics) introduced new concepts for the simultaneous screening of multiple responses to toxicity and are providing novel information on the search for novel biomarkers and on the biological processes triggered by exposure (Snell et al., 2003; Monsinjon and Knigge, 2007).

The biomarker approach combined with bioassay techniques has been regarded as an efficient and cost-effective methodology to assess toxicity of environmental contaminants (Lam and Gray, 2003). With respect to testing methodologies, it has been recognized that laboratory bioassays eliminate the variability from environmental confounding factors, therefore probably permitting a more clear-cut relationship between contamination and toxicity, however, it is also acknowledged that these assays tend to either underestimate or overestimate toxicity (Martín-Díaz et al., 2004). Nevertheless, little research is dedicated to the direct comparison between laboratory and in situ (field) bioassays with fish for the purpose of ERA on aquatic sediments, even though the adequate choice of testing procedures is yet another pillar of toxicity assessment.

The study area, the river Sado estuary (western Portugal) is one of the largest estuarine basins in Portugal (second only to the Tagus estuary, where the capital, Lisbon, is situated), with an approximate area of $240 \mathrm{~km}^{2}$. Although a considerable portion of the estuary is environment-protected, the area has long been subjected to many forms of human usage and alteration, many of which are sources of pollutants that are discharged into the estuary, being considered one of the most important industrial areas in Portugal. The area includes the city of Setúbal $(\approx 100,000$ inhabitants) which is served by an important commercial harbour and a dense heavy-industry belt that includes chemical plants, a paper mill, a thermoelectrical unit, mineral ore storage and shipping facilities and a large shipyard complex (Fig. 1). The estuary is also important for local fisheries, tourism, mariculture and upstream agriculture from which runoffs likely carry pesticides and fertilizers to the estuary. Reinforcing the need to apply effective environmental management and conservation policies, there is the need to protect the only surviving estuarine population of the bottlenose dolphin (Tursiops truncatus) in Portugal (see Caeiro et al., 2009, for an ecological risk assessment strategy for the estuary). Although in global terms the estuary can be regarded as moderately contaminated, some sections, especially those located near industrial areas and the lower estuary revealed levels of concern for many contaminants, both organic and inorganic, with adverse toxicological consequences to organisms being found in recent surveys (e.g. Neuparth et al., 2005). Besides the contamination of the water body from urban and industrial origins and subsequent contaminant trapping in sediments, it is believed that most metallic contamination is driven by river transportation, since the Sado crosses an important pyrite mining region (Cortesão and Vale, 1995, 1996). Endocrine disruptor compounds (EDCs) have also been recently surveyed in the estuary, with the results revealing globally low levels and likely insufficient to cause adverse effects to organisms (Ribeiro et al., 2009), with similar results being found for mercury (Lillebø et al., 2010).

The Senegalese sole (S. senegalensis, Kaup 1858; Teleostei: Pleuronectiformes) is a common soleid in the estuary (that acts an important nursery ground for this and other piscine species) exhibiting a pronounced seasonal variation in its distribution with a tendency to occupy the inner areas of the estuary, preferring sandy-muddy floors where it feeds on small invertebrates (Cabral, 2000). Levels of concern for organic and inorganic contaminants were found in these areas (Caeiro et al., 2005; Lobo et al., 2010). The species has a considerable economical value for local fisheries, as in SW Europe and benefits from a good potential for aquaculture activities (see Dinis et al., 1999), which facilitates access to hatchery-brood animals for research purposes. In the past decade, several bioassay-based ecotoxicological studies have appeared using this species, ranging from more baseline toxicological surveys (e.g. Arellano et al., 1999; Costa et al., 2010a, 2010b) to environmental monitoring (Jiménez-Tenorio et al., 2007) and even toxicological studies of relevance for aquaculture (Osuna-Jiménez et al., 2009). The rising number of ecotoxicological studies using the species as test organism may be providing it with the potential for the monitoring of aquatic sediments that other flatfish species are acknowledged with, such as the flounder (Platichthys flesus) in Northern Europe.

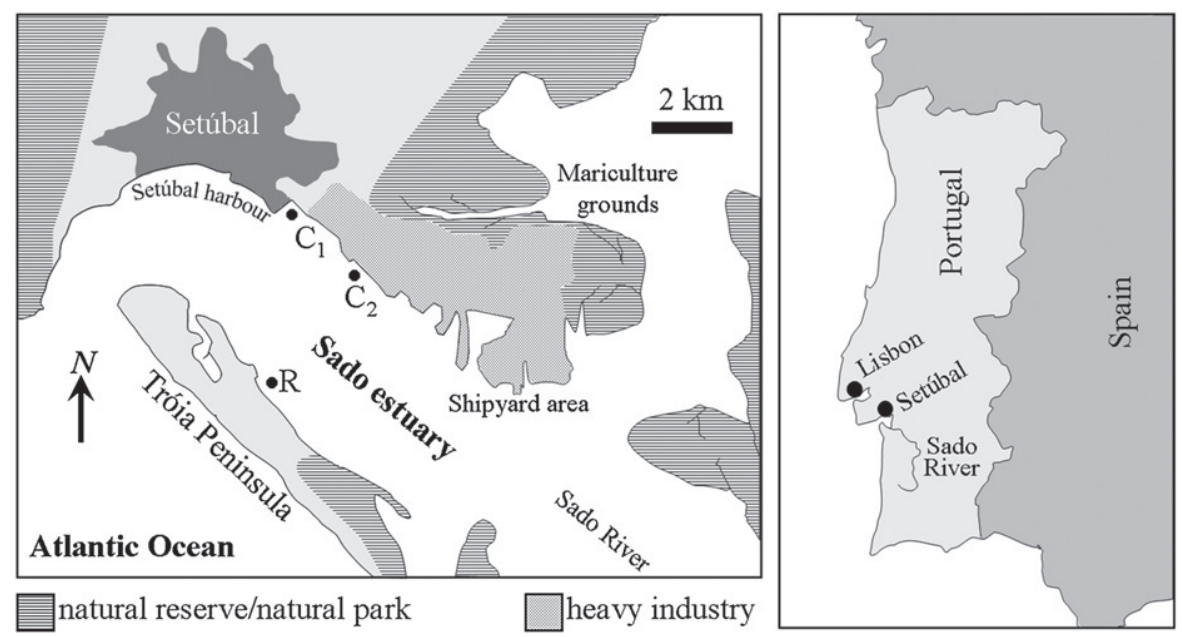

Fig. 1. Map of the study area marking $(\bullet)$ the three sites under survey: $R$ (reference), and contaminated $\left(C_{1}\right.$ and $\left.C_{2}\right)$. 
This work reviews and integrates previous data obtained for sediment contamination profiles with biomarker analyses performed on S. senegalensis exposed to sediments from the Sado estuary. It is intended to assess the constraints and assets of laboratory and field bioassays for the assessment of sediment risk and the adequacy of the multi-level biomarker approach employed and to contribute to a better understanding of the complex biological mechanisms of response to sediment-bound contaminants and their mixtures. The present study will mainly focus on the biomarker (or potential biomarker) significance and validation to determine sediment risk, under a comparative approach between reference and contaminated sediments.

\section{Methods and materials}

\subsection{Study sites}

Three sites of the Sado estuary with potentially different characteristics were chosen for the survey (Fig. 1), according to previous studies that characterized the area for sediment contamination and ecological risk (Caeiro et al., 2005; Neuparth et al., 2005; Costa et al., 2008a). The reference site (R) is located off the Tróia peninsula environmental protected area and is the farthest from pollution sources. The contaminated sites $C_{1}$ and $C_{2}$ were chosen for their distinct characteristics: site $\mathrm{C}_{1}$ is located at the Setúbal commercial harbour, in an area of low hydrodynamics and high water residence time while site $C_{2}$ is located off the industrial belt, between the city and a large shipyard facility.

\subsection{Experimental procedures}

Two series of time-displaced 28-day bioassays with juvenile hatchery-bred Solea senegalensis as test species (all individuals from the same cohort) were performed. A first series was done under controlled laboratory conditions with sediments from the three sites collected in November 2006 (termed "fall" assay). The following series comprised simultaneous laboratory and field (in situ) tests during April-May 2007 ("spring" assay). Sediment samples were collected with a grab and divided for the laboratory assays and for contaminant determination.

The laboratory assays were performed in duplicate in white 15-L capacity polyvinyl tanks with blunt edges in which were allocated $2 \mathrm{~L}$ of fresh sediment plus $12 \mathrm{~L}$ of clean seawater. The parameters were similar between fall and spring assays, and are described in detail by Costa et al. (2008b, 2011c). In brief: temperature and photoperiod were held constant at $\approx 18^{\circ} \mathrm{C}$ and $12: 12 \mathrm{~h}$, respectively. Salinity, pH and ammonia were restrained at approximately 33,8 and $2 \mathrm{mg} \mathrm{L}^{-1}$, respectively, by means of a weekly $25 \%$ water volume change (toxic unionized ammonia was restrained at $\approx 0.05 \mathrm{mg} \mathrm{L}^{-1}$ ). A recirculation arrangement and constant aeration were adapted to the test tanks with the flows being adjusted to minimize resuspension. Dissolved $\mathrm{O}_{2}$ was $\approx 50 \%$. Twenty (spring) or twenty-four (fall) fish (standard length class $\approx 60-70 \mathrm{~mm}$ ) were allocated per tank. Weather conditions at the study area did not allow performing in situ assays during the fall. Field assays were done the following spring with submerged cages $(90 \times 90 \times 30 \mathrm{~cm})$ lined with a $5 \mathrm{~mm}$ plastic mesh. Each cage was divided in two compartments, each being regarded as a replicate. Twenty animals were allocated in each compartment. The cages were placed over the bottom by scuba diving, ensuring contact with the sediment, at depths ranging between 7 and $9 \mathrm{~m}$. For all assays, at days $14\left(\mathrm{~T}_{14}\right)$ and $28\left(\mathrm{~T}_{28}\right)$, five to six fish per replica were retrieved and sampled for biological analysis. Ten to twelve soles collected directly from the rearing tanks were also sampled ( $T_{0}$ fish) to establish the baseline condition of the animals.

\subsection{Sediment characterization}

From the sediments collected for the fall assays the metalloid arsenic (As) and the metals cadmium $(\mathrm{Cd})$, chromium $(\mathrm{Cr})$, copper $(\mathrm{Cu})$, lead $(\mathrm{Pb})$ nickel $(\mathrm{Ni})$, and zinc (Zn) were determined by inductively coupled plasma mass spectrometry (ICP-MS) after acid digestions in Teflon vials, according to Caetano et al. (2007), to which were added, in spring, the non-metal selenium (Se) plus the metals cobalt (Co) and manganese ( $\mathrm{Mn})$, quantified by the same procedure; plus mercury $(\mathrm{Hg})$, determined by atomic absorption spectrometry (AAS) from undigested dry samples according to Costley et al. (2000). Element quantification were validated by analysis of the reference sediments MESS-2 and PACS-2 (National Research Council, Canada) and MAG-1 (US Geological Survey, USA) by the same procedures. The measured values were found to be within the certified range.

Organic contaminants were determined in dried samples of sediments collected at both fall and spring assays, namely polycyclic aromatic hydrocarbons (PAHs), polychlorinated biphenyls (PCBs) and the pesticide dichloro-diphenyl-trichloroethane (DDT). Sediment PAHs were determined by gas chromatography-mass spectrometry (GC-MS) as described by Martins et al. (2008), after Soxhlet-extraction with an acetone + hexane mixture, with seventeen 3- to 6-ring PAHs being quantified. Organochlorines (18 PCB congeners and DDT plus its main metabolites, meaning $p p^{\prime} \mathrm{DDT}$ plus $p p^{\prime} \mathrm{DDD}$ and $p p^{\prime} \mathrm{DDE}$ ) were quantified by GC with electron capture detection (GC-ECD) following Soxhlet-extraction with $n$-hexane and fractioning in a chromatographic column as described by Ferreira et al. (2003). The procedures were validated by analysis of the SRM 1941b reference sediment (National Institute of Standards and Technology, USA) and the obtained values were found within the certified range.

Sediment redox potential (Eh) was measured immediately after sediment collection. Sediment fine fraction (FF, particle size $<63 \mu \mathrm{m}$ ) was determined after sediment disaggregation with pyrophosphate and hydraulic sieving. Total organic matter (TOM) was extrapolated from carbon loss-on-ignition (LOI) at $500 \pm 50{ }^{\circ} \mathrm{C}$. The TOM and FF levels are given as a percentage of sediment total dry mass. Further details on the procedures described above are given by Costa et al. (2008a,2008b).

\subsection{Biological analyses and biomarker approach}

The data hereby integrated are described in a series of previous studies (Table 1). The biomarker approach has been subdivided in two major categories: biomarkers of "exposure" and biomarkers of "effect" (Martín-Díaz et al., 2004). The details on the techniques are described elsewhere. In brief: genotoxicity biomarkers were analysed in fall and spring assays by means of the alkaline version of the single-cell gel electrophoresis ("comet") assay to determine total DNA strand breakage (Singh et al., 1988) and through the analysis of erythrocytic nuclear abnormalities (ENA) using a fluorescence microscopy method (Costa and Costa, 2007), both in peripheral blood. Histopathological analysis was achieved by obtaining individual liver histopathological condition indices $\left(\mathrm{I}_{\mathrm{h}}\right)$, adapted from Bernet et al. (1999) that integrated several potential histological biomarkers such as necrosis, hepatocellular alterations and the presence of intraplasmatic inclusions (termed degeneration) in hepatocytes (e.g. lipid vacuoles and hyaline degeneration). The indices are obtained for each individual and are estimated based on the attribution of an importance factor, or weight, to each histopathological change. The weight values range between 1 (low severity, such as inflammatory changes) to 3 (high severity such as necrosis). Details on the surveyed histological traits and their significance are debated by Costa et al.

Table 1

Biomarker approach summary per assay type and respective data sources.

\begin{tabular}{|c|c|c|c|c|c|c|}
\hline Assay season & Assay type & Biomarker type & Biomarker & Target & Method & Data origin \\
\hline \multirow[t]{5}{*}{ Fall } & \multirow[t]{5}{*}{ Laboratory } & \multirow[t]{3}{*}{ Exposure } & Total DNA strand breakage & Whole-blood & Comet assay & Costa et al. (2008b) \\
\hline & & & Chromosomal clastogenesis & Mature erythrocytes & ENA sorting & Costa et al. (2008b) \\
\hline & & & Histopathological biomarkers & Liver & Histopathological indices & Costa et al. (2009b) \\
\hline & & \multirow[t]{2}{*}{ Effect } & MT induction & Liver & DPP-SMDE & Costa et al. (2009a) \\
\hline & & & CYP1A induction & Liver & ELISA & Costa et al. (2009a) \\
\hline \multirow[t]{10}{*}{ Spring } & \multirow[t]{5}{*}{ Laboratory } & \multirow[t]{3}{*}{ Exposure } & Total DNA strand breakage & Whole-blood & Comet assay & Costa et al. (2011c) \\
\hline & & & Chromosomal clastogenesis & Mature erythrocytes & ENA sorting & Costa et al. (2011c) \\
\hline & & & Histopathological biomarkers & Liver & Histopathological indices & Costa et al. (2011a) \\
\hline & & \multirow[t]{2}{*}{ Effect } & MT induction & Liver & qRT-RT PCR & Costa et al. (2011b) \\
\hline & & & CYP1A induction & Liver & qRT-RT PCR & Costa et al. (2011b) \\
\hline & \multirow[t]{5}{*}{ Field } & \multirow[t]{3}{*}{ Exposure } & Total DNA strand breakage & Whole-blood & Comet assay & Costa et al. (2011b) \\
\hline & & & Chromosomal clastogenesis & Mature erythrocytes & ENA sorting & Costa et al. (2011b) \\
\hline & & & Histopathological biomarkers & Liver & Histopathological indices & Costa et al. (2011a) \\
\hline & & \multirow[t]{2}{*}{ Effect } & MT induction & Liver & qRT-RT PCR & Costa et al. (2011b) \\
\hline & & & CYP1A induction & Liver & qRT-RT PCR & Costa et al. (2011b) \\
\hline
\end{tabular}




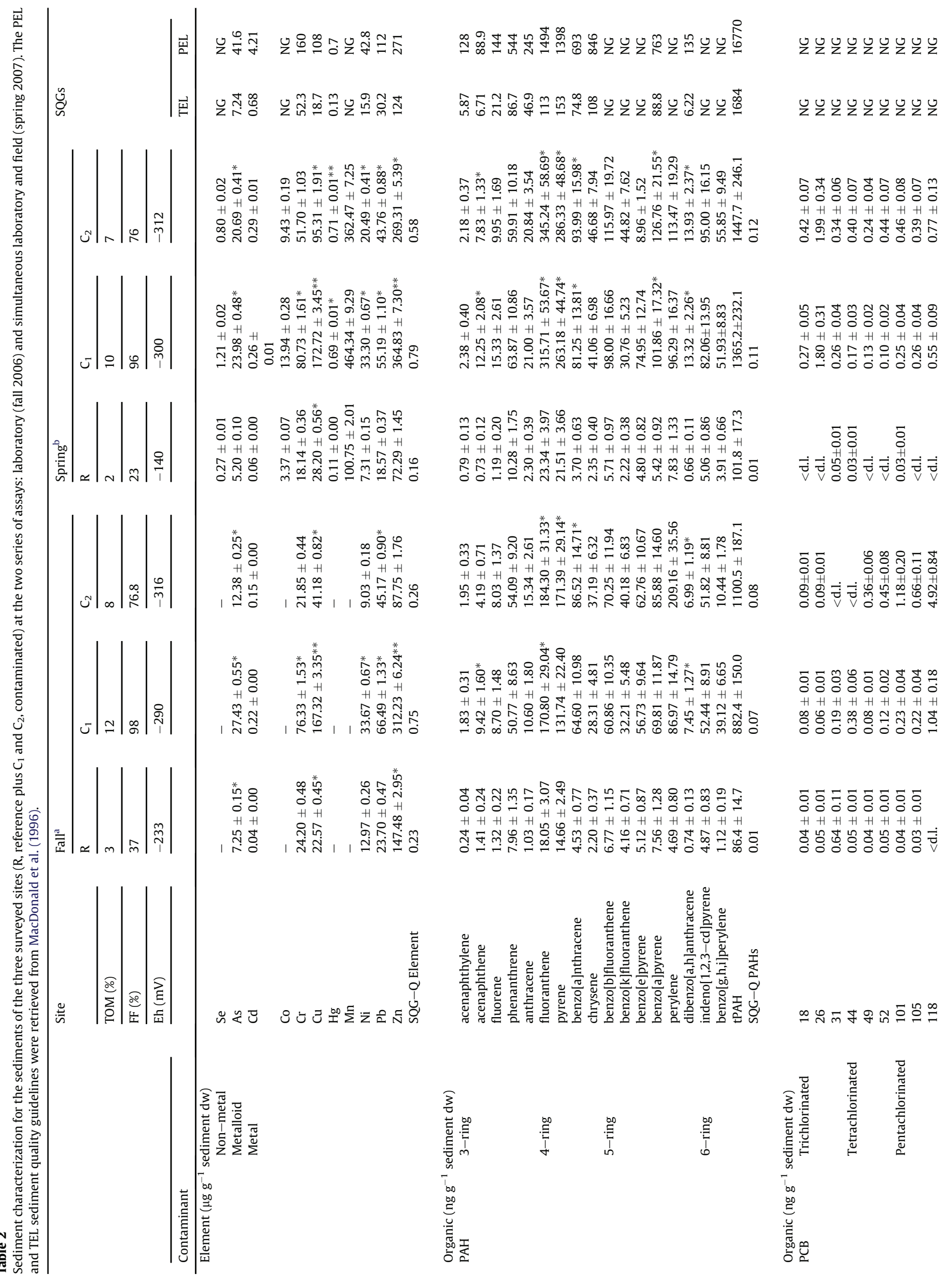




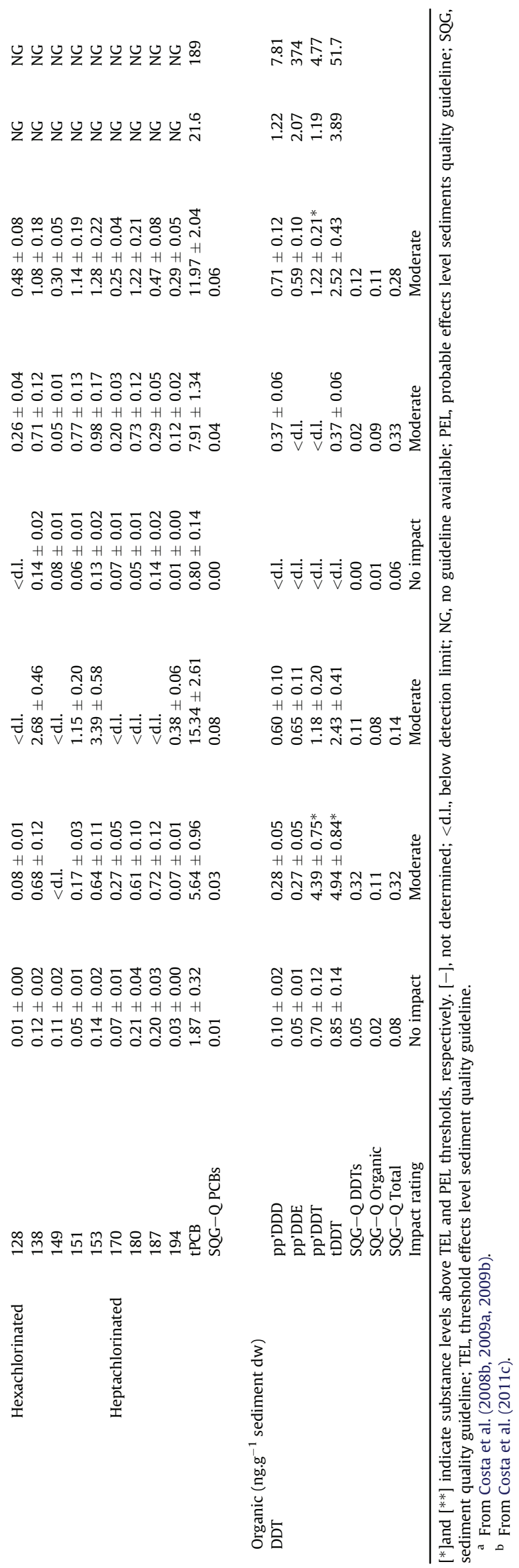

(2009b, 2011a). The $\mathrm{I}_{\mathrm{h}}$ indice shall be throughout regarded as a single "biomarker". Since the most representative alterations correspond to lesions (Costa et al., 2009b, 2011a), histopathological alterations were included, as for genotoxicity, in the biomarkers of effect category.

Two (potential) biomarkers of exposure were analysed in both sets of assays: cytochrome P450 1A and thiolic protein (metallothionein-like) induction. The induction of CYP1A (cytochrome P450 1A) protein in liver was determined by enzyme-linked immunosorbent assay (ELISA) in the microsomal fraction of homogenates, according to Nilsen et al. (1998) in the fall assays, and by quantitative real-time reverse transcription polymerase chain reaction (qRT-RT PCR) in the spring assays, after Solea senegalensis sequencing of the CYP1A1 gene (GenBank accession GU946412) and design of sequence-specific primers (Costa et al., 2011b). Metallothionein-like protein induction in the liver was determined by differential pulse polarography with a static mercury drop electrode (DPP-SMDE), as described by Costa et al. (2008a) and by qRT-RT PCR as aforesaid (Costa et al., 2011b), after MT1 (metallothionein isoform 1) gene sequencing and specific primer design (GenBank accession GU946410). The analysis of hepatic MT1 and CYP1A1 transcription is part of a toxicogenomic approach (Costa et al., 2011b) that comprised also the analysis of the caspase 3 apoptosis-related gene (CASP3, GenBank accession HQ115741), catalase (CAT, GU946411), Glutathione peroxidase 1 (GPx, HM068301) all first-time sequenced cDNAs for the species, to which was added the heat-shock protein $90 \mathrm{kDa}$ alpha (HSP90AA/ $\alpha$, AB367526), first characterized by Manchado et al. (2008) for S. senegalensis. The changes in gene transcription were estimated taking $\mathrm{T}_{0}$ animals as the calibrator group, from the relative transcription ratios estimated according to Pfaffl (2001). The toxicogenomic approach performed on spring-tested soles was complemented by the analysis of hepatocyte apoptosis through the TUNEL (TdT-mediated dUTP-X nick end labelling) reaction on paraffin-embedded sections. The hepatic apoptotic indice (AI) is expressed as the number of TUNEL-positive cells per section $\mathrm{mm}^{2}$. Complementarily, a proteomic survey was performed on the livers of fish tested in the spring assays (assayed in the laboratory and in situ) to screen changes in cytosolic proteins' regulation patterns, though the combination of two-dimensional electrophoresis (2DE) with tandem mass spectrometry techniques (Costa et al., submitted for publication). As previously, $\mathrm{T}_{0}$ fish were considered as the calibrator group in order to obtain protein regulation fold change. For simplification (and analytical) purposes, and due to the potentially higher specificity of these responses to a contaminant group or group of contaminants, all biomarker responses related to gene expression or protein induction are allocated in the biomarkers of exposure category.

\subsection{Statistics and integration of data}

The integration of sediment contamination data was based on the sediments' potential impact to cause adverse biological effects, estimated by calculating the PEL quotient (PEL-Q) based on the published guideline values for coastal waters, namely the threshold effects level (TEL) and the probable effects level (PEL), according to MacDonald et al. (1996). The PEL-Q indice was obtained for each contaminant or class of contaminants (depending on available data) according to the formula described by Long et al. (1998):

PEL $-\mathrm{Q}_{\mathrm{i}}=\frac{\mathrm{C}_{\mathrm{i}}}{\mathrm{PEL}}$

The PEL value is the guideline value for the contaminant $i$ and $C_{\mathrm{i}}$ the effective measured concentration of the contaminant in the sediment. The Sediment Quality Guideline Quotient indice (SQG-Q), developed to compare sites impacted by mixtures of contaminants, was calculated for each sediment (according to Long et al., 1998) as:

$\mathrm{SQG}-\mathrm{Q}=\frac{\sum_{i=1}^{n} \mathrm{PEL}-\mathrm{Q}_{\mathrm{i}}}{n}$

Where PEL- $\mathrm{Q}_{\mathrm{i}}$ is the indice deriving from formula (1) for the ith contaminant and $n$ the number of surveyed contaminants. The three sites were scored according to their overall potential of observing adverse biological effects according to the criteria: SQG-Q $<0.1$ - unimpacted; $0.1 \leq \mathrm{SQG}-\mathrm{Q}<1$ - moderately impacted; SQG-Q $\geq 1$ - highly impacted (MacDonald et al., 2004).

For statistical purposes, all biomarker data were converted into fold change (FC) relative to $\mathrm{T}_{0}$ fish (which in essence reflect the rearing conditions) in order to obtain a relative measure of change imposed by laboratory and field exposures to the sediment of all surveyed sites, reference included. Average fold change was estimated for biomarkers of effect and responses for comparison purposes. The Mann-Whitney $U$ test was employed for pairwise comparisons between experimental conditions. The integration of SQG-Qs with biomarker data was achieved by factor analysis with extraction by principal components. Cluster analysis based on the 1-Pearson correlation statistic $r$ was done to survey links between biological responses and effects. All statistics were performed with the software Statistica (Statsoft). A significance level of $\alpha=0.05$ was set for all analyses.

In order to assess the consistency of each measured response and effect to detect significant differences between fish exposed to contaminated and clean 
(reference) sediments, a biomarker consistency indice $\left(\mathrm{B}_{\mathrm{i}}\right)$ was developed, being defined as:

$\mathrm{B}_{\mathrm{i}}=\frac{\sum_{j=1}^{n} \mathrm{~s}_{\mathrm{j}}}{n}$

Being $\mathrm{B}_{\mathrm{i}}$ the biomarker consistency index for the ith response or effect, $n$ the number of cases in the experimental subset under scope and $\mathrm{s}_{\mathrm{j}}$ the "score" for the jth case, which can attain the value of -1 if a significant decrease in the response was observed (Mann-Whitney $U, p<\alpha$ ); 1 if a significant increase was observed or 0 if no statistical differences between exposure to contaminated and reference sediments were detected.

\section{Results}

\subsection{Sediment characterization}

The reference sediment $\mathrm{R}$ remained the least contaminated sediment from fall to spring. However, the overall contamination of sediment $C_{2}$ increased, due to higher levels of metals and arsenic (Table 2). Still, sediments from site $C_{1}$ contained the highest load of organic matter and particle fine fraction and sediment $C_{2}$ was found to be the most anoxic, at both seasons. Although total $\mathrm{Hg}$ was not determined at the fall assays, the contribution of this metal to the overall SQG-Q of sediments $C_{1}$ and $C_{2}$ was low (even though in both cases total Hg surpassed TEL and PEL levels, respectively), since the SQG-Q for total contamination without the consideration of total $\mathrm{Hg}$ (for the spring assays) was 0.31 and 0.24 for sediment from sites $\mathrm{C}_{1}$ and $\mathrm{C}_{2}$, respectively. Although the differences between the two contaminated sediments diminished from fall to spring even though site $C_{1}$ remained the most contaminated (especially by metals), followed by site $C_{2}$ (the most contaminated by organic xenobiotics). The reference sediment revealed low contamination levels, with decreased SQG-Qs from fall to spring. The essential metals copper and zinc plus the metalloid arsenic were consistently the elements of most concern at both seasons, inclusively reaching TEL levels in site $\mathrm{R}$ in the fall.

For both batches of sediments the phenanthrene/anthracene and fluoranthene/pyrene ratios were found to be $>1$ and $<10$, respectively, which indicates that the PAHs are mostly of pyrolytic origin (combustion-derived) and not petrogenic (Budzinski et al., 1997). At both seasons, the 4-ring PAHs fluoranthene (in $C_{1}$ and $C_{2}$ ) plus pyrene and benzo(a)anthracene (only in $C_{2}$ in the fall) presented levels of concern, to which is added the 5-ring dibenzo(a,h)anthracene. In the spring, the 5-ring, known carcinogen, benzo(a)pyrene reached TEL levels in the two contaminated sediments. Overall, the PAH concentrations in sediments $C_{1}$ and $C_{2}$ were higher in the spring comparing to the previous fall, with the inverse being observed for the reference sediment. Four-ring PAHs were always the most representative substance of the class, ranging approximately between 40 and $50 \%$ of total PAHs.

Regarding sediment organochlorines, different patterns were observed between the two seasons. While penta- and hexachlorinated biphenyls where the best represented chlorinated biphenyls (CBs) in sediments from sites $C_{1}$ and $C_{2}$ in the fall (trichlorinated in the reference sediment), ranging approximately between 25 and $50 \%$, in the following spring the pentachlorinated compounds lost their prevalence to trichlorinated CBs ( $\approx 20-30 \%)$ in the two contaminated sites. The levels of DDTs were also dissimilar, with sediment $C_{1}$ presenting the highest concentration in the fall and $C_{2}$ in the spring. The pp'DDT compound was always, however, the most representative DDT.

\subsection{Biomarker approach}

Distinct patterns of biomarker fold change (FC) were observed between seasons, assay type and sampling time, besides between

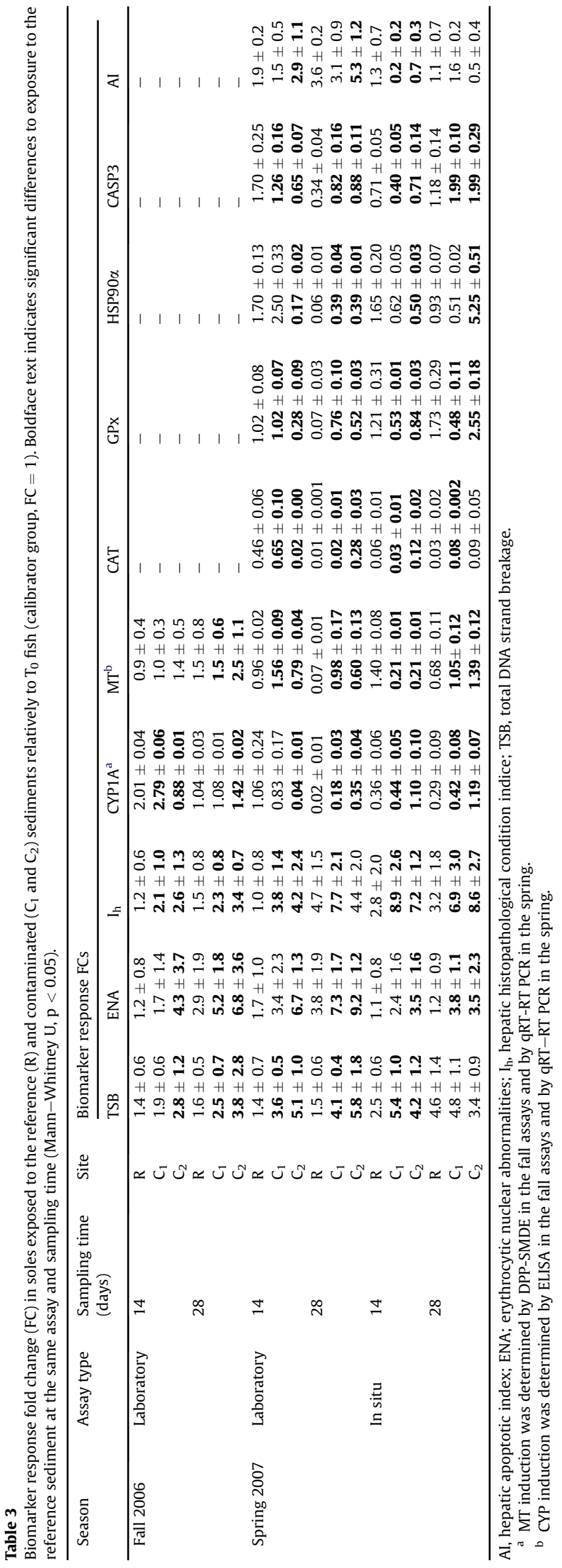



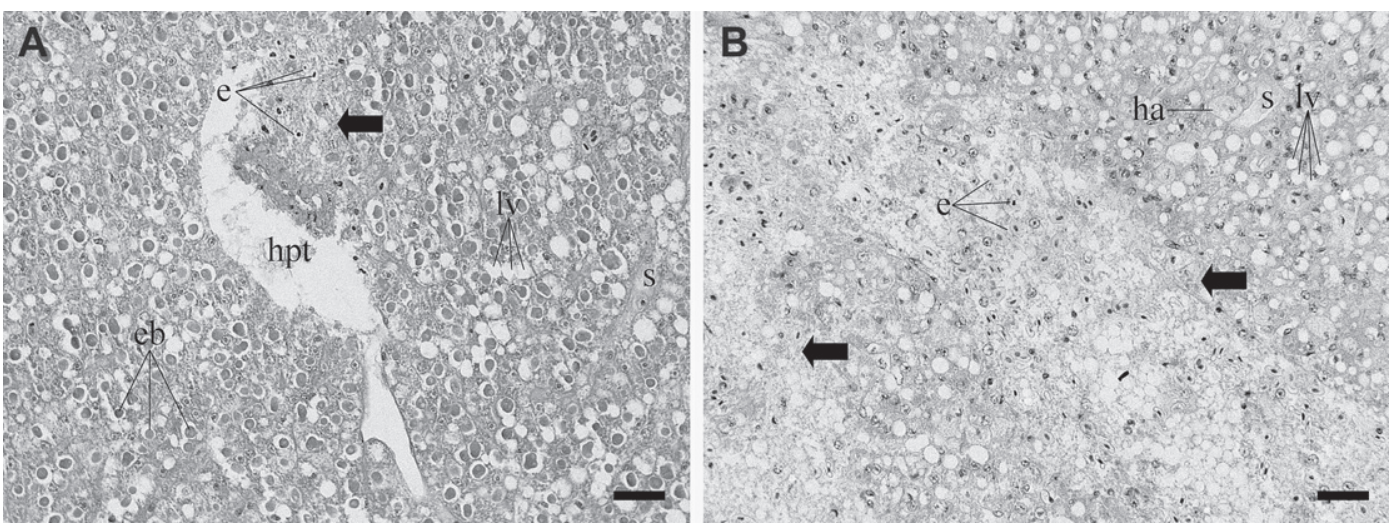

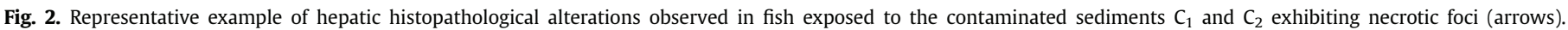

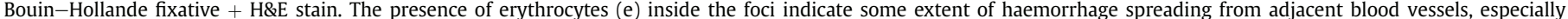

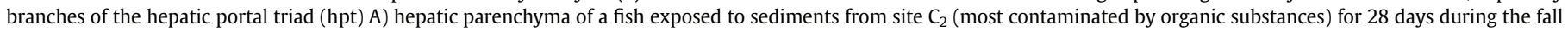

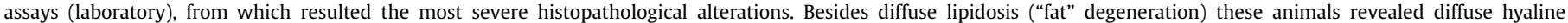

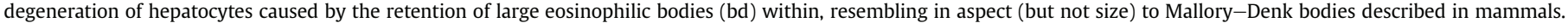

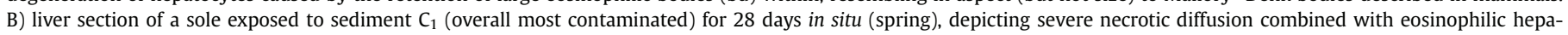

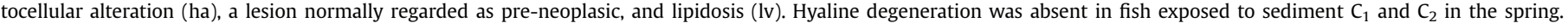
S) indicate sinusoid vessels.

exposure to the three surveyed sediments (Table 3 ). Exposure to the contaminated sediments $C_{1}$ and $C_{2}$ consistently elicited more significant differences to FCs. In both series of laboratory assays, exposure to the contaminated sediments for 28 days yielded more significantly different responses comparatively to the respective exposure to sediment R. Also, the increase in the FCs is overall more evident for biomarkers of effect than those of exposure, regardless of assay type and season. The most severe DNA damage (given either by TSB or ENA analyses) relatively to initial-state $\left(T_{0}\right)$ fish was found in laboratory-exposed animals (with significant differences to R-tested fish also) to sediment $\mathrm{C}_{2}$ (most contaminated by organic pollutants) for 28 days, at both seasons. However, the most severe histopathological changes were observed in the livers of fish exposed in the spring for 28 days to sediments $C_{1}$ (in the laboratory assays) and, especially, $\mathrm{C}_{2}$ (in situ) (Fig. 2). The induction of protein content or gene transcription, on the other hand, revealed variable trends concerning the increase or decrease of responses in all assays, yielding a tendency to downregulate at $\mathrm{T}_{14}$ in animals exposed to the contaminated sediments comparatively to $T_{0}$, and, most notably, to R-tested fish in both laboratory and in situ bioassays. Hepatocyte apoptosis (measured only in the spring assays) was only significantly increased in laboratory-exposed fish to sediment $C_{2}$ in relation to the reference treatment whereas in the field assays, a significant decrease was observed at $\mathrm{T}_{14}$ in fish exposed to the two contaminated sediments comparing to R-tested soles.

By combining the results from the two seasons by averaging the FCs for the same surveyed biomarkers of effect (TSB, ENA and $I_{h}$ ) and exposure (CYP1A and MT induction, even though these were surveyed by different methods), it was observed that there is a greater contribution to change in relation to $T_{0}$ animals caused by the biomarkers of effect (Fig. 3). Factorial analysis on these same data plus the sediment SQG-Qs, again combining fall and spring assays, showed that the average variation of the biomarkers of effect correlates best with the sediments' potential to cause adverse effects to organisms with respect to global and in situ assay conditions whereas laboratory assays revealed a less clear pattern between variables (Fig. 4). The factor loadings obtained for the factor analysis main functions $\mathrm{F} 1(\approx 50-70 \%$ total explained variance) and F2 ( $\approx 20-30 \%$ total explained variance) sustain that the average FC of the considered biomarkers of effect is better correlated to SQG-Qs for registering positive values in F1 as the sedimentrelated variables, especially in field assays (with a loading of 0.91). The average FC for the biomarkers of exposure, on the other hand, provided a significant negative contribution to F1 in the field assays

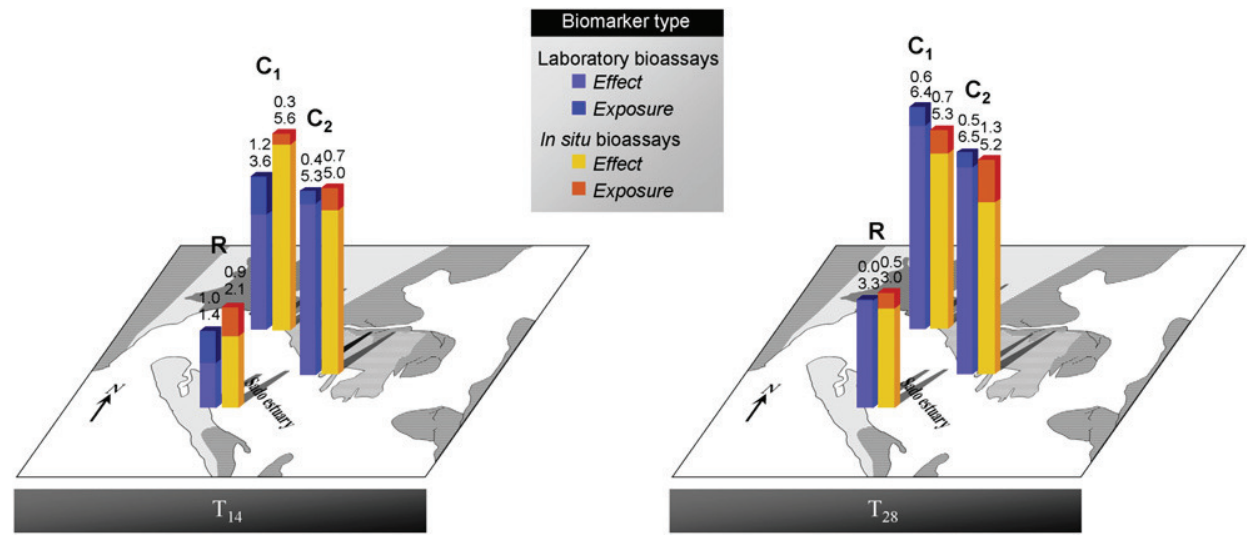

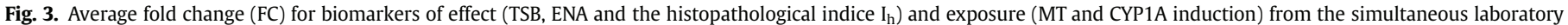

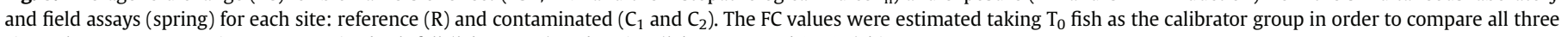
sites. The average FC estimates comprise both fall (laboratory) and spring (laboratory and in situ) bioassays. 

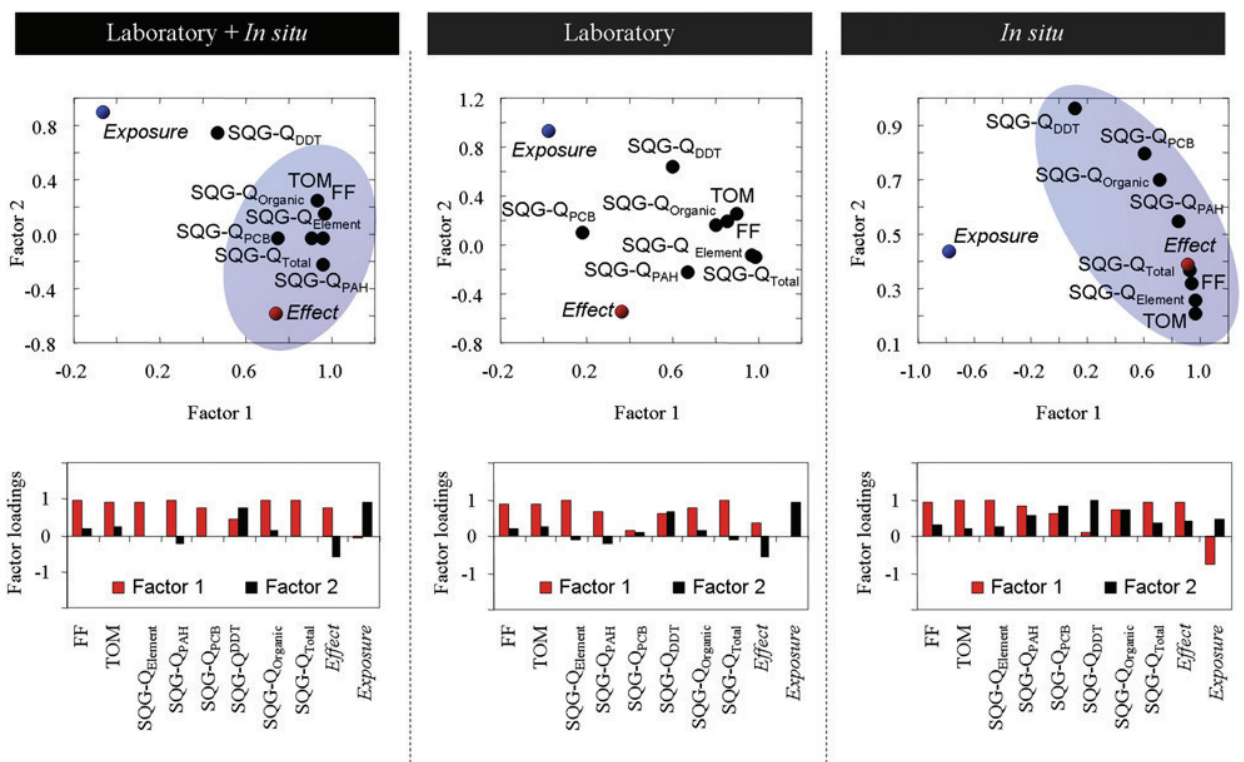

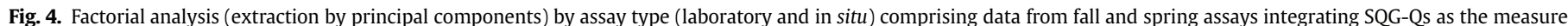

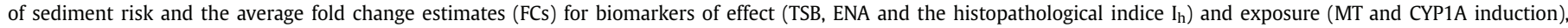
estimated considering $\mathrm{T}_{0}$ animals as the calibrator group.

(with a loading of -0.78 ), which indicates a negative link to the biomarker of effect variables. Regarding the laboratory assays, the average FC for the biomarkers of exposure revealed a more significant contribution to F2 (factor loading $=0.95$ ) with an opposite trend to that for biomarkers of effect, similar to the global analysis results. Overall, the loadings should indicate that the variation of the biomarkers of exposure has a significant role in explaining the total variance, however linked to unknown variables.

\subsection{Global evaluation of biomarker responses}

On Fig. 5 are indicated the estimates of the $B_{i}$ indice [3] for each biomarker response, grouped by experimental subset. The results indicate that the biomarkers reflecting lesions (TSB, ENA and $\mathrm{I}_{\mathrm{h}}$ ) were globally more consistent in detecting significant differences between exposure to contaminated and clean sediments than protein content and gene transcription responses for both seasons. However, transcription of the CAT and CYP1A genes were revealed to be more consistent than the transcription of other toxicologically-relevant genes in the spring assays. There were differences in biomarker response consistency in fall and spring assays upon grouping sampling time and site: in the fall assays only $\mathrm{I}_{\mathrm{h}}$ could consistently distinguish exposure to contaminated from uncontaminated sediments at $\mathrm{T}_{14}$ whereas at $\mathrm{T}_{28}$ genotoxicity biomarkers also had perfect consistency. Exposure to sediment $\mathrm{C}_{2}$ (mostly contaminated by organic xenobiotics) in the same series of assays also revealed better consistency than tests with sediment $C_{1}$ (most contaminated by metals) for all biomarkers except CYP1A

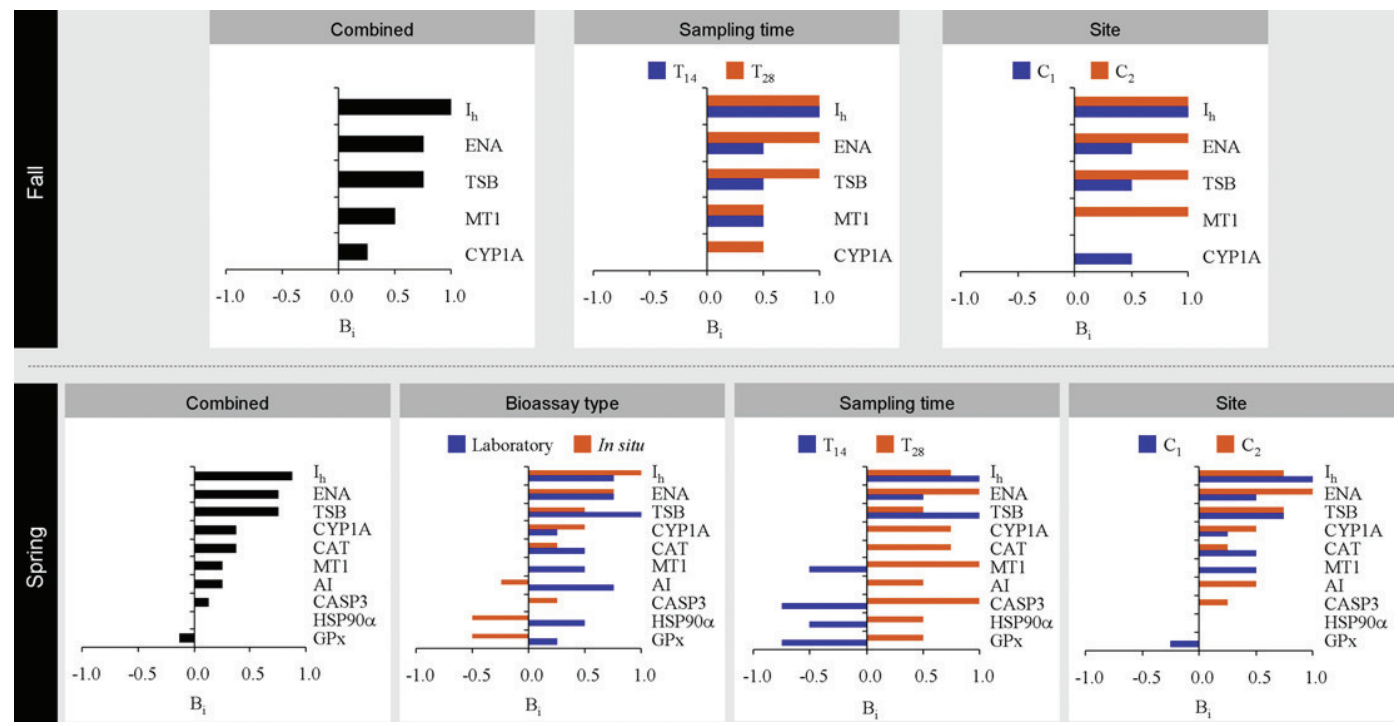

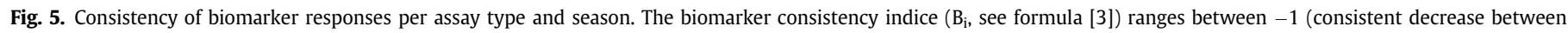
exposure to the contaminated and the reference sediments per experimental subset) and 1 (consistent increase). 
induction. Regarding the spring assays, biomarker consistency was more variable outside the biomarker of effect group, with some transcript responses yielding opposite trends, such as for HSP90 $\alpha$ and GPX in laboratory versus field and these plus MT1 and CASP3 in $\mathrm{T}_{14}$ versus $\mathrm{T}_{28}$ subsets, showing that some of these responses could be significantly decreased as a result of exposure to the contaminated sediments when compared to the reference test after 14 days of exposure. At $T_{28}$, all biomarker responses were more positively consistent. With respect to test $C_{1}$ versus $C_{2}$ subsets, MT1 only revealed some degree of consistency for the assays with sediment $C_{1}$, as AI for assays with sediment $C_{2}$. The HSP90 $\alpha$ response did not reveal any consistency $\left(B_{\mathrm{i}}=0\right)$ for either case.

\subsection{Integration of multi-level responses}

The proteomic screening detected nineteen deregulated cytosolic proteins in soles exposed to sediments through laboratory and in situ bioassays for 14 days (Costa et al., submitted). The matched proteins related to several functions, from anti-oxidative defence (e.g. 1-CysPrx) to gene transcription (TE2B) and energy production (Table 4). Correlation-based cluster analysis combining all measured responses from fish tested at spring collected at $\mathrm{T}_{14}$ (laboratory and in situ assays) retrieved two major clusters (Fig. 6). The first cluster includes the FCs for all considered biomarkers of effect (TSB, ENA and $I_{h}$ ), the apoptotic indice and the FCs for the regulation of LDH and 1-CysPrx enzymes. The second cluster includes the remaining responses and can, on its turn, be subdivided in two other clusters. With the exception of CYP1A transcription, the FCs for the remaining genes were found in the same cluster, together with the regulation of two energy production-related enzymes (PGAM2 and Eno1), a lipid transporter (ApoA1), trypsinogen 1c (a trypsin protease precursor) and a hypothetic intracellular signalling protein, SPB1.

\section{Discussion}

Although the global contamination levels of sites $C_{1}$ and $C_{2}$ can be regarded of moderate risk, exposure to sediments from these sites caused adverse effects to fish comparatively to exposure to the reference sediment. In accordance, biomarkers that reflect lesions, here designated of "effect", namely histopathological alterations and genotoxicity, better reflected sediment contamination and could therefore be indicative of the actual risk. It has also been demonstrated that the bioassay approach can yield different results when performed under controlled or natural conditions, since external variables, like seasonal changes in sediment characteristics (especially contaminant load) and experimental noise can influence the results. Still, the multi-level biomarker approach here presented was purposeful in the distinction between sediments regarded as uncontaminated from those of risk even though, under the specific circumstances of assessment, establishing accurate cause-effect relationships between specific contaminant concentrations and toxicity remains difficult.

\subsection{Laboratory versus field bioassays}

Although the adequacy of both types of bioassays in monitoring studies has been demonstrated (e.g. Riba et al., 2005), little research has dealt directly with the comparison between laboratory and field bioassays with fish for the monitoring of contaminated sediments. However, differences between the two approaches, with respect to biological responses in benthic fish, have already been reported, as well as the resulting difficulties in assessing experimental noise from true toxicopathic results (e.g. Vethaak et al., 1996; Hatch and Burton, 1999). It has been earlier hypothesized that the combination of low Eh with high FF and TOM contents might have in fact favoured the release of contaminants from the sediments during the laboratory assays as a result of disturbance from collection, handling and also animal-driven resuspension (Costa et al., 2008b, 2009a, 2011c). The combination between disturbance and the anoxic-oxic shift occurring when sediments are exposed to oxygenated water (as occurred during the laboratory experiment) may have favoured the release of substances trapped by organic matter and fine particles back to the water column, therefore increasing bioavailability (see Eggleton and Thomas, 2004). Furthermore, resuspended contaminants tend to persist for an extended time in the water column as a consequence of turbation (Caetano et al., 2003; Atkinson et al., 2007). Field bioassays, by their turn, can be affected by unaccounted background variables that are difficult to manage. For instance, at the spring assays, fish collected at $\mathrm{T}_{28}$ that had been caged at the reference site, revealed unexpectedly higher concentration of lipid peroxides in blood plasma than animals from the contaminated sites with a corresponding increase in whole-blood TSB levels but not ENA (Costa et al., 2011c). The GPx gene transcription was also elevated in these animals (Costa et al., 2011b). This was likely due to increased oxidative stress caused by poor access to food items since in situ R-tested fish for 28 days did not have in their digestive tracts the small gastropods and bivalves that were commonly found in soles exposed at other sites, starvation being a known cause of increased lipid peroxidation due to disrupted lipid metabolism in fish (Morales et al., 2004; Pascual et al., 2003). It can be suspected that food deprivation occurred due to the higher hydrodynamics of the site leading to the observed partial removal of sediment beneath the cages, likely limiting the animals' access to prey. Nevertheless, liver histopathology was not significantly affected as to impair a comparison between the reference test and the tests in the contaminated sites, the similar occurring with other gene transcription responses.

\subsection{Seasonal changes in sediment contamination and potential risk}

Natural interseasonal changes in estuarine sediment geochemical characteristics (e.g. due to between season variation of river runoffs and oceanic influence) is known to affect contaminant concentration and speciation, therefore constituting another constraint in risk assessment (see for instance Flegal et al., 2005). Although the overall levels of contamination were found to have the same magnitude as those from previous studies for the area, shifts were observed from fall to spring assays, the most notorious of which being as the increase of metal concentrations in station $C_{2}$.This increase in metal concentrations in the spring led to the unexpected similarity between SQG-Qs for sites $C_{1}$ and $C_{2}$, regardless of the inclusion of $\mathrm{Hg}$ in the chemical analysis to the sediments, a contaminant that has been regarded of low risk in the area (Lillebø et al., 2010). The Sado river crosses important mining areas (especially for pyrite), which accounts for the levels of some metals found to be elevated in all sites (including the reference), especially copper (refer to Cortesão and Vale, 1995). Seasonal changes were also observed for organic contaminants, namely an increase in total PAHs from fall to spring, a tendency that is opposite to what was inferred from previous research (Neuparth et al., 2005), with pyrene and the highly carcinogenic $\mathrm{B}[\mathrm{a}] \mathrm{P}$ revealing an important increment in potential risk by exceeding TEL. The levels of PCB were low and below the guidelines, with little variation between seasons. For DDTs, however, a significant seasonal variation has been found in site $C_{1}$, the most contaminated by $p$ 'DDT in the fall (above the TEL guideline) but showing a considerable decrease in the spring, losing its rank to sediment $C_{2}$, where no noticeable seasonal variation was observed. The levels of DDTs for this station were consistent with the values found for the lower estuary about a decade ago (Gil and Vale, 1999). 
P.M. Costa et al. / Environmental Pollution 161 (2012) 107-120

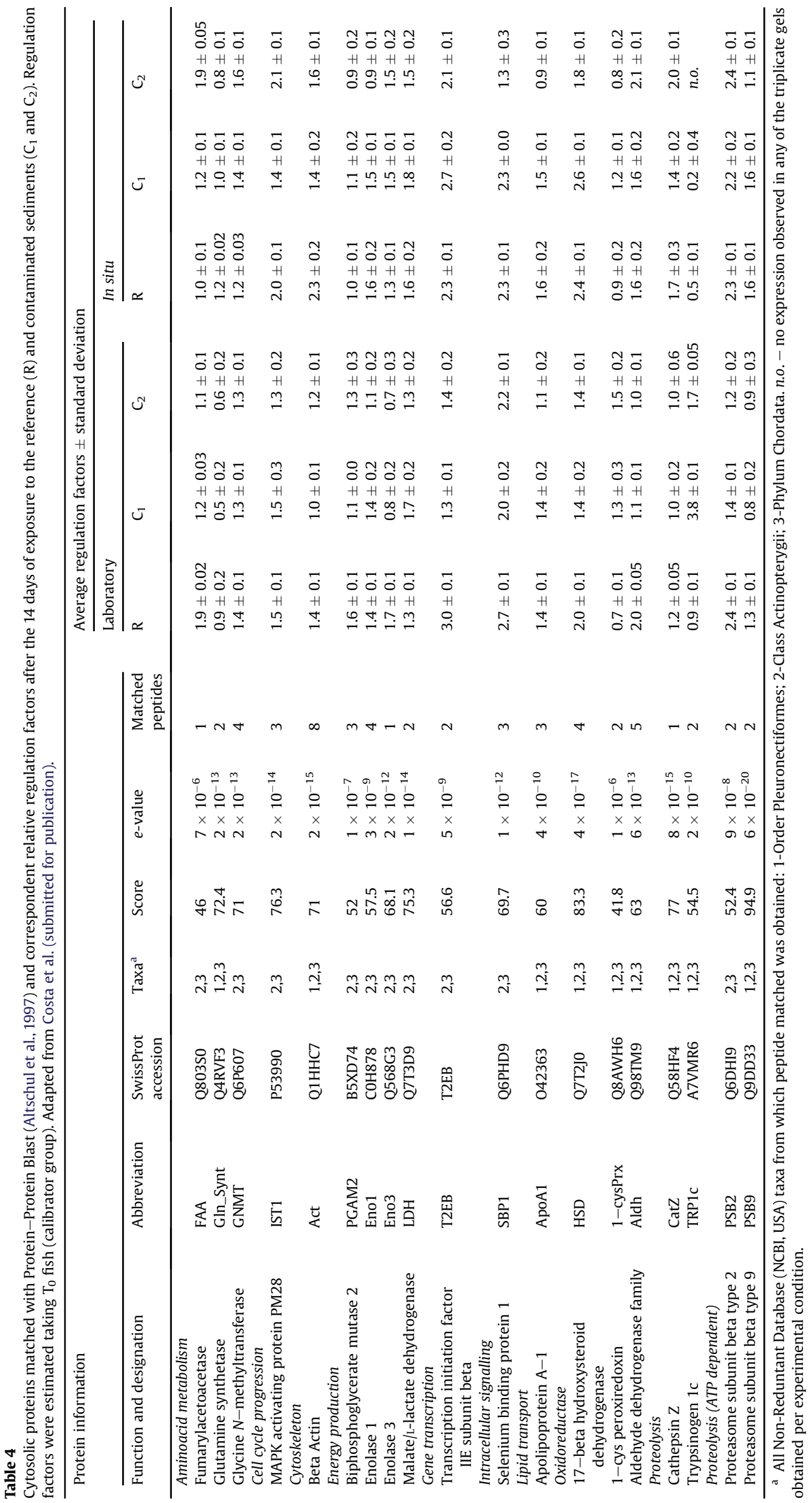




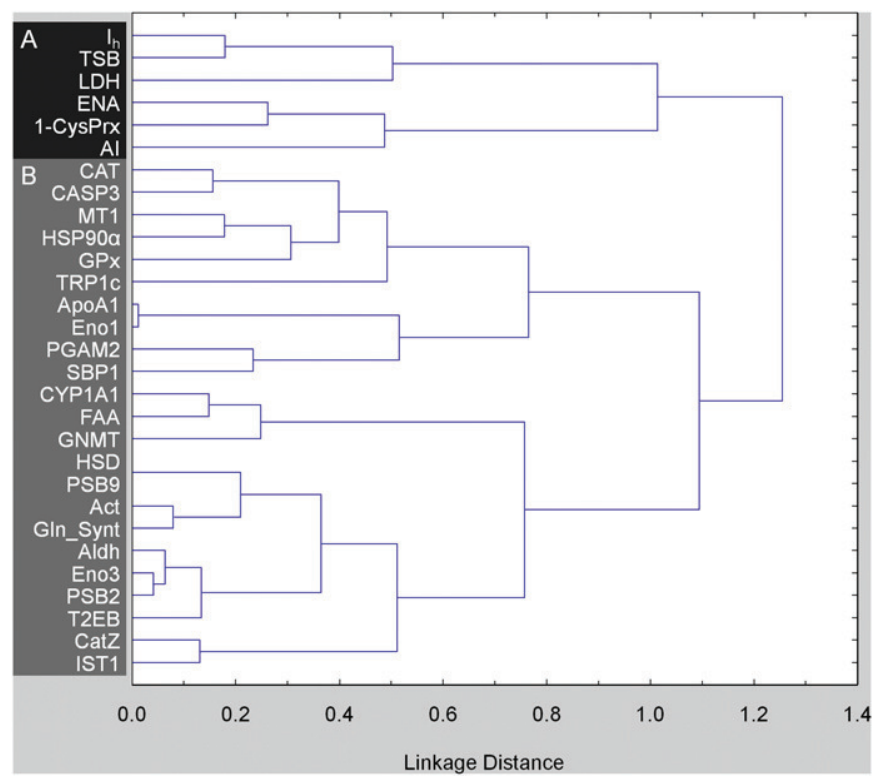

Fig. 6. Correlation-based cluster analysis (1-Pearson $r$ statistic was used as distance metric) combining all hepatic biomarker responses (given as fold change to $T_{0}$ fish) from field- and laboratory- tested fish (April assays) after 14 days of exposure to any surveyed sediment. Un-weighted pair-group average was employed as amalgamation rule. Two major clusters are discernible, A) comprising all considered biomarkers of effect plus the apoptotic indice AI and an oxidoreductase enzyme, 1-cys peroxiredoxin (1-cysPrx), and the lactate dehydrogenase (LDH) energy production-related enzyme and B), which includes all other responses measured by "omic" approaches and that relate to multiple cellular functions, including transcription of MT1, CAT, CYP1A1 and other genes plus several proteins of distinct functions, from proteolysis (e.g. TRP1c and CatZ) to energy production (such as Eno1 and Eno3).

Still, the fluctuations of sediment contamination in the area are in accordance with natural variation reported previous studies (Cortesão and Vale, 1996) and likely contribute to the differences in biomarker response observed between fall and spring bioassays.

\subsection{Possible effects of contaminant interactions on biomarker responses}

Co-exposure to metallic and organic toxicants, especially PAHs, may, in part, explain why adverse effects (i.e. DNA damage and histopathological alterations) were higher in fish exposed to sediment $C_{2}$ than to $C_{1}$ (the most contaminated sediment), most notably in the fall assays, where a greater difference between the contamination levels of the two sediments was evident. Contaminant interactions may result in agonist (meaning that the response is the sum of the individual responses triggered by the contaminants), synergistic (when co-exposure causes a response not achievable by any agent on its own) or antagonist (inhibitory) effects. Antagonist effects between contaminants have already been identified and reported by several authors. It is the case, for instance, of co-exposure to metals and metalloids inhibiting CYP up-regulation and activity by strong inducers such as PAHs (Vakharia et al., 2001; Spink et al., 2002; Sorrentino et al., 2005). Co-exposure to metals and PAHs (e.g. Cd and benzo[a]pyrene, respectively) has also been reported to inhibit apoptosis and even the expression of glutathione peroxidase (Costa et al., 2010b). Accordingly, these biomarkers at some point yielded unexpected lower values in exposed to contaminated sediments in the spring (especially $\mathrm{C}_{2}$, the most contaminated by PAHs but also contaminated by some metals), most notably at $\mathrm{T}_{14}$.

PAHs are liposoluble compounds, detoxified through activation by CYP1A monooxygenase enzymes, which renders them more hydrophilic, thus more easily excretable. However, activated PAHs, such as diol-epoxides, are highly genotoxic and the activation process itself generates reactive oxygen species (ROS) as by-products (e.g. Lemaire and Livingstone, 1997). Apoptosis is known to be triggered by oxidative stress (see Wyllie, 2010, for a recent review). Therefore, impairment of PAH activation can, at a short term, avoid oxidative damage and delay downstream responses to injury such as apoptosis (also termed programmed cell death or PCD) since apoptosis consists of a cytological process that intends to "dismantle" heavily-damaged cells to avoid inflammation and scattering of toxic cellular debris resulting from necrosis and the propagation of mutations. Accordingly, CASP3 (a key effector caspase in the apoptotic process) transcription, apoptosis, DNA and histological damage, although not CYP1A transcription, were observed to be correlated in fish exposed for 14 days in the spring assays (Fig. 6). Peroxiredoxins, also included in this cluster, are thought to be effective anti-oxidant enzymes (Chen et al., 2000), however little surveyed in toxicological studies. Interestingly, an enzyme involved in anaerobic respiration, lactate dehydrogenase (LDH) was also included in this same cluster, which could indicate impairment of oxidative metabolism and aerobic respiration. As an example, LDH activity has been found to increase as a consequence of exposure to styrene in CYP1 deficient mice, therefore with impaired catabolism of this substance (Carlson, 2010).

As another example, there are studies on fish that discuss the potential effects of contaminant interaction on the "classical" MT induction biomarker. For example, there is evidence for synergisms between metals (like $\mathrm{Cd}$ and $\mathrm{Cu}$ ) and B[a]P in sea bass (Roméo et al., 1997) whereas other authors describe MT induction to be suppressed by another PAH (methylcholanthrene) in trout hepatocytes exposed to a combination of metals (Risso-de Faverney et al., 2000). It has also been discussed that in aquatic animals, exposure to low or moderate levels of strong MT inducers, such as Cd, may produce in a complex mixture of contaminants may result in reduced or absent MT overexpression (Costa et al., 2008a; Mouneyrac et al., 2002), which may aid explaining the low or even reduced MT induction in soles exposed to sediment $C_{1}$.

\subsection{Biomarker responses may reflect metabolic disruption}

Biomarkers of exposure provided clearer responses after 28 days exposure, for all bioassays (Fig. 5). In fact, a very significant downregulation of most transcription responses was observed in the spring assays, at $\mathrm{T}_{14}$, some exhibiting the very opposite response at $\mathrm{T}_{28}$ (as for GPX and CASP3). Down-regulation was not, however, positively linked to hepatic lesions. Also, the increase in $\mathrm{I}_{\mathrm{h}}$ was observed to distinguish exposure to contaminated versus uncontaminated sediments for all tests, at $\mathrm{T}_{14}$, revealing very significant liver damage occurring at the assays midterm. At $\mathrm{T}_{28}$ liver lesions lost some of their significance in this distinction, with fish exposed in situ to sediment $C_{2}$ showing signs of recovery at $T_{28}$ (Table 3 ).

Although there is surprisingly little literature regarding the integration of biomarker responses in toxicological stress models some authors have already debated the importance of understanding the stress curves in the interpretation of biomarkers endpoints (Triebskorn et al., 1997). Even considering the differences between all bioassays performed, the animals sampled at $\mathrm{T}_{14}$ (the assays' midterm), were likely still enduring homeostatic and metabolic disturbance triggered by exposure, while fish collected at the end of the assays exhibited ability to respond and perhaps attenuate some of the negative effects (see Steinberg et al., 2008). The proteomic screening performed on $\mathrm{T}_{14}$-collected fish (from the spring assays) is in accordance with this statement since, especially in laboratory-exposed fish to sediments $C_{1}$ and $C_{2}$, most matched 
proteins were down-regulated compared to R-tested or even $\mathrm{T}_{0}$ animals (Table 4).

The reduced or impaired responses observed at $\mathrm{T}_{14}$ displayed by fish exposed to the contaminated sediments compared to those from the reference test likely reflect an initial disturbance phase that derives from exposure and in part to the inevitable change in the animals' environment when they were allocated in the testing apparatus. There followed a recovery phase that should explain the increase in most gene transcription responses at $T_{28}$. These results provide evidence that time of exposure is a decisive factor when interpreting biomarker responses and indicate that null or even lowered responses do not mean absence of stress but rather that metabolic disruption may affect baseline biological mechanisms, from energy production to gene transcription itself (Costa et al., 2011b).

\subsection{Global biomarker evaluation}

Biomarker responses that reflect lesions showed greater consistency in the discrimination between exposure to contaminated and uncontaminated sediments for the specific conjugation of factors that characterize the study sites. Although histopathological alterations do not necessarily mean damage (defence cell intrusion, for instance, may indicate some form of response), the most severe and diffuse histopathological traits analyzed (e.g. necrosis, nuclear pleomorphisms such as hypertrophy and pyknosis and bile duct regression) are considered "regressive" (Bernet et al., 1999), which is in accordance with the generally acknowledged premise that histopathology allows a realistic assessment of organisms' health changes as a consequence of exposure to toxic agents (see $\mathrm{Au}, 2004$, for a review). In addition, the integration of multiple potential histopathological biomarkers into individual weighted condition indices allowed circumventing interindividual variability provided a better estimate of change; since lesions and alterations have different biological significances (refer to Bernet et al., 1999). Damage to DNA, on its turn, is one of the most significant consequences of chemical insult to organisms since it is at the base of neoplasic and pre-neoplasic disease and, if affecting the germ line, may affect the whole population (see Chen and White, 2004; Iarmarcovai et al., 2008; for reviews). It should be noted, though, that single-strand DNA damage can be repaired, which means that TSB is a result between the balance chain breakage and the cellular ability to repair it, which can be compromised by exposure per se (Sarasin, 2003). The results from the present study indicate that juvenile soles did sustain considerable adverse effects to liver tissue and DNA as a consequence of exposure to sediments that are regarded as low to moderately contaminated. Furthermore, with respect to risk assessment, measuring damage-related responses was less affected by the factors discussed above, regardless of their non-specificity to a given contaminant or class of contaminants although it can be inferred that organic contaminants (especially PAHs) played a major role in the adverse effects to fish exposed to sediments $\mathrm{C}_{1}$ and $\mathrm{C}_{2}$.

Biochemical and gene transcription or protein induction endpoints are likely more prone to be affected by confounding factors. The responses here surveyed by "omic" and gene transcription-related techniques are linked to multiple cellular functions, from apoptosis to energy production, proteolysis, lipid transport and many others; and likely take part in an intricate metabolic web. It is the case, for instance, of the role of MTs in the inhibition of the apoptotic cascade presumably by scavenging oxidative radicals (Kondo et al., 1997). Even HSP90 and other HSPs are known to regulate apoptosis (Takayama et al., 2003). Interestingly, the transcription of MT1, HSP90 $\alpha$ (termed inducible HSP90) and CASP3 was found to be correlated with the transcription of CAT and GPx anti-oxidant enzymes (Fig. 6). However, the apoptotic index (AI) was observed to be better correlated to histopathology, showing that molecular responses and tissue alterations may not be linearly related. It should also be noted that classical biomarker responses such as MT and CYP1A induction (determined by protein detection-based assays) tend to provide more clear-cut information when inducing contaminants are well represented. For instance, MT induction in the livers of $S$. senegalensis exposed to sediments from a SW Spanish has been found clearly correlated to metal contamination, however, sediment metal concentrations (especially $\mathrm{Cd}$ and $\mathrm{Zn}$ ) were up to tenfold higher than those presented here, with negligible levels of organic xenobiotics (Jiménez-Tenorio et al., 2007). In addition, the role of proteolytic enzymes should not be disregarded when measuring protein contents (Costa et al., 2010b), since the proteomic survey revealed alterations to the regulation of proteasome (ATP-dependent protease complex) subunits, a trypsin precursor and a cathepsin cysteine protease; all found to be upregulated in most tests. Concerning CYP1A, Hartl et al. (2007) found its activity in the livers of juvenile turbots (as well as DNA strand breakage) well linked to sediment organic contaminants, however, the concentrations of metals in sediments (especially $\mathrm{Cd}, \mathrm{Cu}$ and $\mathrm{Zn}$ ) were more than three times lower than those of the present study. In general, the integration of this information indicates that biomarkers that reflect some sort of response are dependent not only on the presence of multiple contaminants but also likely on some sort of dose-response functions. Still, it should be noticed that CYP1A, CAT and MT1 responses were more effective in detecting differences between exposure to contaminated from uncontaminated sediments than other genes, including GPx. Furthermore, CYP1A transcription was a more consistent biomarker in fish exposed to sediment $\mathrm{C}_{2}$ (most contaminated by PAHs and organochlorines) in situ, while MT1 transcription was more consistent in animals exposed to sediment $\mathrm{C}_{1}$ (most contaminated by metals) in the laboratory. Oppositely, MT and CYP1A assessment by the traditional DPP and ELISA techniques, respectively (which determine protein content), could not be conclusively linked to sediment contamination (see Fig. 5 and Table 2). Analysis of transcripts may be more robust when the conjunction of experimental factors potentially enhances experimental background, since protein content can be affected by postranscriptional factors. It is thus possible that gene transcription analysis has a greater sensitivity for being located upstream in the gene expression pathway, permitting yet some degree of biomarker specificity towards a given type of contaminant when assaying complex mixtures.

\subsection{Concluding remarks}

In spite of the constraints in toxicity assessment of sedimentbound xenobiotics, it was observed that moderately contaminated sediments can elicit adverse effects to benthic fish. Regarding biomarker responses, the combination of moderate levels of contamination with complex contaminant mixtures and experimental noise were important confounding factors that diluted the interassay variation and compromised the determination of cause-effect relationships between responses and specific contaminants. Nevertheless, biomarkers that reflect lesions were consistent to detect differences between contaminated and uncontaminated sediments, therefore providing a measure of risk, regardless of assay type (laboratory or in situ).

The "omic" (proteomic) and transcript analyses permitted a screening of multiple responses, some of which revealed potential for predictive environmental toxicology, such as CASP3 and peroxiredoxin expression, and would benefit from further research. 
These surveys, by integrating multiple responses, gave some insights on the mechanistics of exposure to mixtures of contaminants, namely on the central role of oxidative stress, energy production imbalance and proteolysis. Furthermore, it is clear that different testing conditions, time of exposure and contaminant levels can provoke very different expression patterns, even in genes involved in similar processes, as CAT and GPx are in anti-oxidative defence. Surveying multiple responses can thus aid filling in the gaps when a particular trait fails to produce significant outcomes or reveals results that, at a glance, contradict those predicted by theory.

Both laboratory and field bioassays could differentiate exposure to reference and contaminated sediments but the biomarker analyses revealed that the effects and responses to toxicity resulting from the two approaches can be very distinct. Laboratory studies, however cheaper and more expedite, may globally tend to overestimate toxicity, especially by favouring the release of contaminants trapped in sediments through disturbance. On the other hand, they are not affected by unaccountable environmental variables that introduce experimental noise in the field. Although sediment disturbance events by natural causes such as storms and heavy river runoffs or anthropogenic modifications such as dredgings are common events in estuaries, laboratory studies may thus produce results that are less realistic in ecological terms in steady-state environments, which may render this approach less effective for practical monitoring programmes. Nevertheless, studies under controlled environments remain valuable and expedite for more mechanistic surveys. The choice of the adequate bioassay methodology is, therefore, not an easy one and requires a careful balance between cost, logistics, fundamental objectives and the need to reduce experimental noise with the least prejudice of ecological relevance.

\section{Acknowledgements}

The present research was approved by the Portuguese Science and Technology Foundation (FCT) and POCTI (Programa Operacional Ciência, Tecnologia e Inovação, research project ref. POCTI/AMB $57281 / 104$ ) and financed by FEDER (European Fund for Regional Development). P. M. Costa was supported by FCT grants SFRH/BD/ $28465 / 2006$ and SFRH/BPD/72564/2010. The authors wish to thank E. Chicano-Gálvez, J. Alhama and J. Lopez Barea, (Universidad de Córdoba), C. Miguel (ITQB), M. Diniz (REQUIMTE) and T.S. Neuparth (CIIMAR) for their support. The authors are also thankful to APSS (Administração dos Portos de Setúbal e Sesimbra, SA), RNES (Reserva Natural do Estuário do Sado) and M. Caetano, M. Martins, A. Ferreira, P. Pousão, V. Branco, R. Cesário and J. Raimundo (IPIMAR).

\section{References}

Altschul, S.F., Madden, T.L., Schäffer, A.A., Zhang, J., Zhang, Z., Miller, W., Lipman, D.J. 1997. Gapped BLAST and PSI-BLAST: a new generation of protein database search programs. Nucleic Acids Res. 25, 3389-3402.

Arellano, J.M., Storch, V., Sarasquete, C., 1999. Histological changes and coppe accumulation in liver and gills of the Senegalese sole, Solea senegalensis. Ecotoxicol. Environ. Saf. 44, 62-72.

Atkinson, C.A., Jolley, D.F., Simpson, S.L., 2007. Effect of overlying water $\mathrm{pH}$ dissolved oxygen, salinity and sediment disturbances on metal release and sequestration from metal contaminated marine sediments. Chemosphere 69 1428-1437.

Au, D.W.T., 2004. The application of histo-cytopathological biomarkers in marine pollution monitoring: a review. Mar. Pollut. Bull. 48, 817-834.

Bernet, D., Schmidt, H., Meier, W., Burkhardt-Holm, P., Wahli, T., 1999. Histopathology in fish: a proposal for a protocol to assess aquatic pollution. J. Fish Dis. $22,25-34$.

Budzinski, H., Jones, I., Bellocq, J., Piérard, C., Garrigues, P., 1997. Evaluation of sediment contamination by polycyclic aromatic hydrocarbons in the Gironde estuary. Mar. Chem. 58, 85-97.
Cabral, H.N., 2000. Distribution and abundance patterns of flatfishes in the Sado estuary, Portugal. Estuaries 23, 351-358.

Caeiro, S., Costa, M.H., Ramos, T.B., Fernandes, F., Silveira, N., Coimbra, A., Medeiros, G., Painho, M., 2005. Assessing heavy metal contamination in Sado Estuary sediment: an index analysis approach. Ecol. Indic 5, 151-169.

Caeiro, S., Costa, M.H., DelValls, A., Repolho, T., Gonçalves, M., Mosca, A., Coimbra, A.P., Ramos, T.B., Painho, M., 2009. Ecological risk assessment of sediment management areas: application to Sado estuary, Portugal. Ecotoxicology $18,1165-1175$.

Caetano, M., Madureira, M.J., Vale, C., 2003. Metal contaminated remobilisation during resuspension of anoxic contaminated sediment: short-term laboratory study. Water Air Soil Pollut. 143, 23-40.

Caetano, M., Fonseca, N., Cesário, R., Vale, C., 2007. Mobility of Pb in salt marshes recorded by total content and stable isotopic signature. Sci. Total Environ. 380, 84-92.

Carlson, G.P., 2010. Metabolism and toxicity of styrene in microsomal epoxide hydrolase-deficient mice. J. Toxicol. Environ. Health A 73, 1689-1699.

Chapman, P.M., 2007. Determining when contamination is pollution - Weight of evidence determinations for sediments and effluents. Environ. Int. 33, 492-501.

Chen, J.-W., Dodia, C., Feinstein, S.I., Jain, M., Fisher, A.B., 2000. 1-Cys peroxiredoxin, a bifunctional enzyme with glutathione peroxidase and phospholipase A2 activities. J. Biol. Chem. 275, 28421-28427.

Chen, G., White, P.A., 2004. The mutagenic hazards of aquatic sediments: a review. Mutat. Res. 567, 151-225.

Cortesão, C., Vale, C., 1995. Metals in sediments of the Sado estuary, Portugal. Mar. Pollut. Bull. 30, 34-37.

Cortesão, C., Vale, C., 1996. Seasonal and inter-annual variations of particulate metals in a river contaminated with mine drainage (Sado river, Portugal). Arch. Hydrobiol. 47, 307-314.

Costa, P.M., Costa, M.H., 2007. Genotoxicity assessment in fish peripheral blood: a method for a more efficient analysis of micronuclei. J. Fish Biol. 71 (SA), $148-151$.

Costa, P.M., Repolho, T., Caeiro, S., Diniz, M.E., Moura, I., Costa, M.H., 2008a. Modelling metallothionein induction in the liver of Sparus aurata exposed to metal-contaminated sediments. Ecotoxicol. Environ. Saf. 71, 117-124.

Costa, P.M., Lobo, J., Caeiro, S., Martins, M., Ferreira, A.M., Caetano, M., Vale, C., DelValls, T.A., Costa, M.H., 2008b. Genotoxic damage in Solea senegalensis exposed to sediments from the Sado Estuary (Portugal): effects of metallic and organic contaminants. Mutat. Res. 654, 29-37.

Costa, P.M., Caeiro, S., Diniz, M., Lobo, J., Martins, M., Ferreira, A.M., Caetano, M., Vale, C., DelValls, T.A., Costa, M.H., 2009a. Biochemical endpoints on juvenile Solea senegalensis exposed to estuarine sediments: the effects of contaminant mixtures on metallothionein and CYP1A induction. Ecotoxicology 18, 988-1000.

Costa, P.M., Diniz, M.S., Caeiro, S., Lobo, J., Martins, M., Ferreira, A.M., Caetano, M., Vale, C., DelValls, T.A., Costa, M.H., 2009b. Histological biomarkers in liver and gills of juvenile Solea senegalensis exposed to contaminated estuarine sediments: a weighted indices approach. Aquat. Toxicol. 92, 202-212.

Costa, P.M., Caeiro, S., Diniz, M.S., Lobo, J., Martins, M., Ferreira, A.M., Caetano, M., Vale, C., DelValls, T.À, Costa, M.H., 2010a. A description of chloride cell and kidney tubule alterations in the flatfish Solea senegalensis exposed to moderately contaminated sediments from the Sado estuary (Portugal). J. Sea Res. 64, 465-472.

Costa, P.M., Chicano-Gálvez, E., López Barea, J., DelValls, T.À, Costa, M.H., 2010b. Alterations to proteome and tissue recovery responses in fish liver caused by a short-term combination treatment with cadmium and benzo[a]pyrene. Environ. Pollut. 158, 3338-3346.

Costa, P.M., Caeiro, S., Lobo, J., Martins, M., Ferreira, A.M., Caetano, M., Vale, C., DelValls, T.A., Costa, M.H., 2011a. Estuarine ecological risk based on hepatic histopathological indices from laboratory and in situ tested fish. Mar. Pollut. Bull. 62, 55-65.

Costa, P.M., Miguel, C., Caeiro, S., Lobo, J., Martins, M., Ferreira, A.M., Caetano, M., Vale, C., DelValls, T.À, Costa, M.H., 2011b. Transcriptomic analyses in a benthic fish exposed to contaminated estuarine sediments through laboratory and in situ bioassays. Ecotoxicology. doi:10.1007/s10646-011-0708-z.

Costa, P.M., Neuparth, T., Caeiro, S., Lobo, J., Martins, M., Ferreira, A.M., Caetano, M., Vale, C., DelValls, T.A., Costa, M.H., 2011c. Assessment of the genotoxic potential of contaminated estuarine sediments in fish peripheral blood: laboratory versus in situ studies. Environ. Res. 111, 25-36.

Costa, P.M., Chicano-Gálvez, E., Caeiro, S., Lobo, J., Martins, M., Ferreira, A.M., Caetano, M., Vale, C., Alhama-Carmona, J., Lopez-Barea, J., DelValls, T.À., Costa, M.H., submitted for publication. Hepatic proteome changes in Solea senegalensis exposed to contaminated estuarine sediments: a laboratory and in situ survey.

Costley, C.T., Mossop, K.F., Dean, J.R., Garden, L.M., Marshall, J., Carroll, J., 2000. Determination of mercury in environmental and biological samples using pyrolysis atomic adsorption spectrometry with gold amalgamation. Anal. Chim. Acta 405, 179-183.

Dinis, M.T., Ribeiro, L., Soares, F., Sarasquete, C., 1999. A review on the cultivation potential of Solea senegalensis in Spain and in Portugal. Aquaculture 176, 27-38.

Eggleton, J., Thomas, K.V., 2004. A review of factors affecting the release and bioavailability of contaminants during sediment disturbance events. Environ. Int. 30, 973-980.

Ferreira, A.M., Martins, M., Vale, C., 2003. Influence of diffuse sources on levels and distribution of polychlorinated biphenyls in the Guadiana River estuary, Portugal. Mar. Chem. 89, 175-184. 
Flegal, A.R., Conaway, C.H., Scelfo, G.M., Hibdon, S.A., Sañudo-Wilhelmy, S.A., 2005. A review of factors influencing measurements of decadal variations in metal contamination in San Francisco Bay, California. Ecotoxicology 14, 645-660.

Gil, O., Vale, C., 1999. DDT concentrations in superficial sediments of three estuarine systems in Portugal. Aquat. Ecol. 33, 263-269.

Hatch, A.C., Burton Jr., G.A., 1999. Sediment toxicity and storm water runoff in a contaminated receiving system: consideration of different bioassays in the laboratory and field. Chemosphere 39, 1001-1017.

Hartl, M.G.J., Kilemade, M., Sheehan, D., Mothersil, C., O’Halloran, J., O’Brien, N.M., van Pelt, F.N.A.M., 2007. Hepatic biomarkers of sediment-associated pollution in juvenile turbot, Scophthalmus maximus L. Mar. Environ. Res. 64, 191-208.

Iarmarcovai, G., Ceppi, M., Botta, A., Orsiére, T., Bonassi, S., 2008. Micronuclei frequency in peripheral blood lymphocytes of cancer patients: a meta-analysis. Mutat. Res. 659, 274-285.

Jiménez-Tenorio, N., Morales-Caselles, C., Kalman, J., Salamanca, M.J., de Canales, M.L.G., Sarasquete, C., DelValls, T.A., 2007. Determining sediment quality for regulatory purposes using fish chronic bioassays. Environ. Int. 33, 474-480.

Kondo, Y., Rusnak, J.M., Hoyt, D.G., Settineri, C.E., Pitt, B.R., Lazo, J.S., 1997. Enhanced apoptosis in metallothionein null cells. Mol. Pharmacol. 52, 195-201.

Lam, P.K.S., Gray, J.S., 2003. The use of biomarkers in environmental monitoring programmes. Mar. Pollut. Bull. 46, 182-186.

Lemaire, P., Livingstone, D.R., 1997. Aromatic hydrocarbon quinone-mediated reactive oxygen species production in hepatic microsomes of the flounder (Platichthys flesus L.). Comp. Biochem. Physiol. C 117, 131-139.

Lillebø, A.I., Coelho, P.J., Pato, P., Válega, M., Margalho, R., Reis, M., Raposo, J. Pereira, E., Duarte, A.C., Pardal, M.A., 2010. Assessment of mercury in water, sediments and biota of a southern European estuary (Sado estuary, Portugal). Water Air Soil Pollut. 214, 667-680.

Lobo, J., Costa, P.M., Caeiro, S., Martins, M., Ferreira, A.M., Caetano, M., Cesário, R. Vale, C., Costa, M.H., 2010. Evaluation of the potential of the common cockle (Cerastoderma edule L.) for the ecological risk assessment of estuarine sediments: bioaccumulation and biomarkers. Ecotoxicology 19, 1496-1512.

Long, E.R., Chapman, P.M., 1985. A sediment quality triad: measures of sediment contamination, toxicity and infaunal composition in Puget Sound. Mar. Pollut. Bull. 16, 405-415.

Long, E.R., Field, L.J., MacDonald, D.D., 1998. Predicting toxicity in marine sediments with numerical sediment quality guidelines. Environ. Toxicol. Chem. 17, 714-727.

MacDonald, D.D., Carr, S., Calder, F., Long, E., Ingersoll, C., 1996. Development and evaluation of sediment quality guidelines for Florida coastal waters. Ecotoxicology 5, 253-278.

MacDonald, D.D., Carr, R.S., Eckenrod, D., Greening, H., Grabe, S., Ingersoll, C.G., Janicki, S., Janicki, T., Lindskoog, R.A., Long, E.R., Pribble, R., Sloane, G., Smorong, D.E., 2004. Development, evaluation, and application of sediment quality targets for assessing and managing contaminated sediments in Tampa Bay, Florida. Arch. Environ. Contam. Toxicol. 46, 147-161.

Manchado, M., Salas-Leiton, E., Infante, C., Ponce, M., Asensio, E., Crespo, A. Zuasti, E., Cañavate, J.P., 2008. Molecular characterization, gene expression and transcriptional regulation of cytosolic HSP90 genes in the flatfish Senegalese sole (Solea senegalensis Kaup). Gene 416, 77-84.

Martín-Díaz, M.L., Blasco, J., Sales, D., DelValls, T.A., 2004. Biomarkers as tools to assess sediment quality. Trend. Anal. Chem. 23, 807-818.

Martins, M., Ferreira, A.M., Vale, C., 2008. The influence of Sarcocornia fruticosa on retention of PAHs in salt marshes sediments (Sado estuary, Portugal). Chemosphere $71,1599-1606$.

Monsinjon, T., Knigge, T., 2007. Proteomic applications in ecotoxicology. Proteomics 7, 2997-3009.

Morales, A.E., Pérez-Jiménez, A., Hidalgo, M.C., Abellán, E., Cardenete, G., 2004. Oxidative stress and antioxidant defenses after prolonged starvation on Dentex dentex liver. Comp. Biochem. Phys. C 139, 153-161.

Mouneyrac, C., Amiard, J.C., Amiard-Triquet, C., Cottier, A., Rainbow, P.S., Smith, B.D. 2002. Partitioning of accumulated trace metals in the talitrid amphipod crustacean Orchestia gammarellus: a cautionary tale on the use of metallothioneinlike proteins as biomarkers. Aquat. Toxicol. 57, 225-242.

Neuparth, T., Correia, A.D., Costa, F.O., Lima, G., Costa, M.H., 2005. Multi-level assessment of chronic toxicity of estuarine sediments with the amphipod Gammarus locusta: I. Biochemical endpoints. Mar. Environ. Res. 60, 69-91.
Nilsen, B.M., Berg, K., Goksøir, A., 1998. Induction of cytochrome P450 1A (CYP1A) in fish-a biomarker for environmental pollution. In: Phillips, I.R., Shephard, E.A (Eds.), Methods in Molecular Biology: Cytochrome P450 Protocols. Humana Press Inc., Totowa, pp. 423-438.

Osuna-Jiménez, I., Williams, T.D., Prieto-Álamo, M.-J., Abril, N., Chipman, K. Pueyo, C., 2009. Immune- and stress-related transcriptomic responses of Solea senegalensis stimulated with lipopolysaccharide and copper sulphate using heterologous cDNA microarrays. Fish Shell. Immunol. 26, 699-706

Pascual, P., Pedrajas, J.R., Toribio, F., López-Barea, J., Peinado, J., 2003. Effect of food deprivation on oxidative stress biomarkers in fish (Sparus aurata). Chem.-Biol. Interact 145, 191-199.

Pfaffl, M.W., 2001. A new mathematical model for relative quantification in real-time RT-PCR. Nucleic Acids Res. 29, E45.

Riba, I., Blasco, J., Jiménez-Tenorio, N., González de Canales, M.L., DelValls, TA , 2005. Heavy-metal bioavailability and effects: II. Histopathology-bioaccumulation relationships caused by mining activities in the Gulf of Cádiz (SW, Spain). Chemosphere 58, 671-682.

Ribeiro, C., PardalÂ., M., Tiritan, M.E., Rocha, E., Margalho, R.M., Rocha, M.J., 2009. Spatial distribution and quantification of endocrine-disrupting chemicals in Sado river estuary. Portugal. Environ. Monit. Assess. 159, 415-427.

Risso-de Faverney, C., Lafaurie, M., Girard, J.-P., Rahmani, R., 2000. Effects of heavy metals and 3-methylcholanthrene on expression and induction of CYP1A1 and metallothionein levels in trout (Oncorhynchus mykiss) hepatocyte cultures. Environ. Toxicol. Chem. 19, 2239-2248.

Roméo, M., Cosson, R.P., Gnassia-Barelli, M., Risso, C., Stien, X., Lafaurie, M., 1997. Metallothionein determination in the liver of the sea bass Dicentrarchus labrax treated with copper and B(a)P. Mar. Environ. Res. 44, 275-284.

Sarasin, A., 2003. An overview of the mechanisms of mutagenesis and carcinogenesis. Mutat. Res. 544, 99-106.

Singh, N.P., McCoy, M.T., Tice, R.R., Schneider, E.L., 1988. A simple technique for quantitation of low levels of DNA damage in individual cells. Exp. Cell. Res. 175 184-191.

Snell, T.W., Brogdon, S.E., Morgan, M.B., 2003. Gene expression profiling in ecotoxicology. Ecotoxicology 12, 475-483.

Sorrentino, C., Roy, N.K., Courtenay, S.C., Wirgin, I., 2005. Co-exposure to metals modulated CYP1A mRNA inducibility in Atlantic tomcod Microgadus tomcod from two populations. Aquat. Toxicol. 75, 238-252.

Spink, D.D., Katz, B.H., Hussain, M.M., Spink, B.C., Wu, S., Liu, N., Pause, R. Kaminsky, R.P., 2002. Induction of CYP1A and CYP1B1 in T47-D human breast cancer cells by benzo[a]pyrene is diminished by arsenite. Drug Metab. Dispos. 30, 262-269.

Steinberg, C.E.W., Stürzenbaum, S.R., Menzel, R., 2008. Genes and environment Striking the fine balance between sophisticated biomonitoring and true functional environmental genetics. Sci. Total Environ. 400, 142-161.

Takayama, S., Reed, J.C., Homma, S., 2003. Heat-shock proteins as regulators of apoptosis. Oncogene 22, 9041-9047.

Triebskorn, R., Köhler, H.-R., Honnen, W., Schramm, M., Adams, S.M., Müller, E.F. 1997. Induction of heat shock proteins, changes in liver ultrastructure and alterations of fish behavior: are these biomarkers related and are they useful to reflect the state of pollution in the field? J. Aquat. Ecosys. Stress Recov. 6, $57-73$.

Vakharia, D.D., Liu, N., Pause, R., Fasco, M., Bessette, E., Zhang, Q.-Y., Kaminsky, L.S., 2001. Polycyclic aromatic hydrocarbon/metal mixtures: effect on PAH induction of CYP1A1 in human HEPG2 cells. Drug Metab. Dispos. 29, 999-1006.

van der Oost, R., Beyer, J., Vermeulen, N.P.E., 2003. Fish bioaccumulation and biomarkers in environmental risk assessment: a review. Environ. Toxicol. Pharmacol. 13, 57-149.

van Gestel, C.A.M., van Brummelen, T.C., 1996. Incorporation of the biomarker concept in ecotoxicology calls for a redefinition of terms. Ecotoxicology 5, 217-225.

Vethaak, A.D., Jol, J.G., Meijboom, A., Eggens, M.L., Ap Rheinalt, T., Wester, P.W., van de Zande, T., Bergman, A., Dankers, N., Ariese, F., Baan, R.A., Everts, J.M., Opperhuizen, A., Marquenie, J.M., 1996. Skin and liver diseases induced in flounder (Platichthys flesus) after long-term exposure to contaminated sediments in large-scale mesocosms. Environ. Health Perspect. 104, 1218-1229.

Wyllie, A.H., 2010. "Where, o death, is thy sting?" A brief review of apoptosis biology. Mol. Neurobiol. 42, 4-9. 